\title{
Dexamethasone Treatment for Covid-19, a Curious Precedent Highlighting a Regulatory Gap
}

\author{
Lucia Gozzo ${ }^{1}$, Laura Longo ${ }^{1}$, Daniela Cristina Vitale ${ }^{1}$ and Filippo Drago ${ }^{1,2,3 *}$ \\ ${ }^{1}$ Clinical Pharmacology Unit, Regional Pharmacovigilance Centre, University Hospital of Catania, Catania, Italy, ${ }^{2}$ Department of \\ Biomedical and Biotechnological Sciences, University of Catania, Catania, Italy, ${ }^{3}$ Centre for Research and Consultancy in HTA \\ and Drug Regulatory Affairs, University of Catania, Catania, Italy
}

Keywords: dexamethasone, COVID19, drug repurposing, off-label, European Medicines Agency

\section{INTRODUCTION}

The centralized marketing authorization issued by the European Medicines Agency (EMA) valid in all European Union (EU) Member States has been introduced with the Council Regulation (EEC) No. 2309/93 (Council Regulation, 1993), and improved and amended by the Regulation (EC) No. 726/2004 (Regulation EC, 2004), which introduced the obligation of the procedure for some

OPEN ACCESS

Edited by:

Jean-Marie Boeynaems,

Université libre de Bruxelles, Belgium

Reviewed by:

Brian Godman,

University of Strathclyde,

United Kingdom

*Correspondence:

Filippo Drago

f.drago@unict.it

Specialty section:

This article was submitted to

Pharmaceutical Medicine and

Outcomes Research,

a section of the journal

Frontiers in Pharmacology

Received: 28 October 2020

Accepted: 11 November 2020

Published: 30 November 2020

Citation:

Gozzo L, Longo L, Vitale DC and Drago F (2020) Dexamethasone

Treatment for Covid-19, a Curious

Precedent Highlighting a

Regulatory Gap.

Front. Pharmacol. 11:621934.

doi: 10.3389/fphar.2020.621934 products, including treatment for viral diseases. Therefore, all the drugs and vaccines developed for Covid-19 must be approved according to this approach to be marketed throughout the EU.

Moreover, in order to deal with the emergency and expedite drug and vaccine development for Covid-19, EMA implemented several rapid procedures in addition to those already provided with the standard "accelerated assessment" (Supplementary Material A1).

Conversely, EMA has no power in pricing and reimbursement decisions, which remain the responsibility of the national competent authorities, due to the heterogeneity of the specific national health system (NHS) organization and financial resources.

According to the Article three of the Regulation (EC) No. 726/2004, application for each marketing authorization shall be submitted by the company to the Agency which will issue an opinion through the Committee for Medicinal Products for Human Use (CHMP). This Committee is solely responsible for releasing the opinions (publicly accessible) on all matters about medicinal products for human use.

Moreover, the Article five of the Regulation provides for the possibility that the Executive Director of the European Medicines Agency (EMA) or the European Commission (EC) or a Member State can request the CHMP to formulate an opinion on issues of particular relevance concerning medicinal products for human use.

Supplementary Material A2 shows EMA opinions issued till October 2020 according to Article five of Regulation 726/2004. Almost $60 \%$ of the queries concerned safety issues, in general or in special populations (e.g., elderly, pediatric patients, pregnant women).

More than half of the assessments were required by the Executive Director of the EMA or by EC and about $40 \%$ by national authorities.

On July 2020, CHMP started to review the data concerning the use of dexamethasone in patients with Covid-19 (EMA, 2020a) at the request of the EMA Executive Director following a discussion with European experts belonging to the Covid-19 EMA pandemic task force (COVID-ETF).

In the light of the results of the review, the Committee concluded that dexamethasone can be considered a treatment option for patients who require oxygen therapy (including supplemental oxygen and mechanical ventilation; EMA, 2020b). 


\section{Evidence Supporting Dexamethasone Use in Covid-19 and European Positive Opinion}

The available data assessed were those of the RECOVERY (Randomised Evaluation of COVid-19 thERapY) study arm, which provided for the use of dexamethasone as add-on therapy to the standard of care of hospitalized patients with Covid-19.

The RECOVERY study (University of Oxford, 2020) is a randomised, controlled, open-label, multicenter (involving 176 National Health Service organizations in the United Kingdom), adaptive trial designed to assess the effects of potential treatments in adults patients hospitalized with Covid-19, receiving invasive or non-invasive ventilation, and those receiving or not oxygen. The study is supported by the National Institute for Health Research-Clinical Research Network (NIHR-CRN), which funds high-quality health and care research in England.

According to the adaptive design, an independent Committee was responsible for the assessment of the interim trial results, which would be made available to the public in case of strong evidence on mortality. Moreover, in this case or if other candidate therapeutics with supporting evidence should be evaluated, the trial arms would have been amended accordingly.

One of the first version of the protocol provided the following arms (RECOVERY, 2020a):

- no additional treatment

- lopinavir-ritonavir

- interferon $\beta$

- low-dose corticosteroids

- hydroxychloroquine.

In a subsequent version the interferon $\beta$ arm has been deleted and replaced by azithromycin one (RECOVERY, 2020b). In addition, the new protocol allowed a second randomization (no additional treatment vs. tocilizumab) for patients with evidence of hyper-inflammatory state (RECOVERY, 2020c).

Then the trial design was further modified, and eligible patients were allocated simultaneously to no additional treatment vs. convalescent plasma vs. synthetic neutralizing antibodies (RECOVERY, 2020d).

Finally on June 2020, the interim analysis showed important (and opposite) results which led to the withdrawal of three arms (RECOVERY, 2020e):

- Dexamethasone arm due to the demonstration of death reduction by up to one third in hospitalized patients with severe respiratory complications of Covid-19.

- Lopinavir-ritonavir and hydroxychloroquine due to the lack of clinical benefit (RECOVERY Collaborative Group, 2020).

The trial continues randomization to groups receiving azithromycin, tocilizumab, or convalescent plasma.

Overall 6,425 patients $(89 \%$ with a laboratory-confirmed SARS-CoV-2 infection) were enrolled and randomized to receive either dexamethasone (2,104 patients) or usual care alone (4,321 patients) (RECOVERY Collaborative Group, 2020).
Among randomized patients, $60 \%$ required oxygen therapy, $16 \%$ invasive mechanical ventilation or extracorporeal membrane oxygenation, and $24 \%$ neither.

The primary endpoint was the mortality at 28 days was significantly lower in the dexamethasone group (22.9\% death) than in the comparator one $(25.7 \%$; rate ratio, $0.83 ; 95 \%$ confidence interval [CI], 0.75 to 0.93 ; $\mathrm{P}<0.001$ ). In particular, the difference between groups was clear for patients receiving invasive mechanical ventilation $(29.3$ vs. $41.4 \%$; rate ratio, 0.64 ; 95\% CI, 0.51-0.81) and in those receiving supplementary oxygen without invasive mechanical ventilation (23.3 vs. $26.2 \%$; rate ratio, 0.82; 95\% CI, 0.72-0.94).

On the contrary, no reduction in the risk of death was obtained with the administration of dexamethasone in patients who were not receiving any respiratory support ( 17.8 vs. $14.0 \%$; rate ratio, 1.19; 95\% CI, 0.91-1.55). Moreover, the duration of hospitalization in the dexamethasone group was shorter than those in the usual care group especially among patients mechanically ventilated at randomization (rate ratio $1.48 ; 95 \%$ CI $1.16,1.90$ ), or receiving oxygen (rate ratio, 1.15; 95\% CI 1.06-1.24), with no benefit in patients not receiving oxygen (rate ratio, 0.96; 95\% CI 0.85-1.08).

These results are supported by additional published data, including a meta-analysis conducted by the World Health Organization (WHO), reporting data from seven clinical studies about the use of corticosteroids for the treatment of patients with Covid-19 (WHO Rapid Evidence Appraisal for Covid-19 Therapies (REACT) Working Group, 2020). The analysis included a total of 1703 patients randomized to receive systemic corticosteroids (dexamethasone, hydrocortisone, or methylprednisolone; $\mathrm{n}=678$ ) or usual care or placebo (1,025 patients). The primary endpoint was all-cause mortality at 28 days after randomization.

The study results show a reduced risk of death at 28 days among patients randomized to corticosteroids compared with standard of care or placebo [summary OR, 0.66 (95\% CI, 0.53-0.82); $\mathrm{P}<0.001$ based on a fixed-effect meta-analysis].

Therefore, an inexpensive and commonly used steroid is the first drug showing to prevent deaths from Covid-19 (Ledford 2020).

Based on the data described above, EMA endorsed the use of dexamethasone (oral or injectable) in adults and adolescents (from 12 years of age and weighing at least $40 \mathrm{~kg}$ ) who require supplemental oxygen therapy, at the recommended dose of $6 \mathrm{mg}$ once a day for up to 10 days (EMA, 2020c).

\section{From European Approval to Patients' Access}

The procedure under the Article five of the Regulation has allowed to recommend an extension of the use of a product already on the market. This is the first time that a new indication is approved through this procedure. Previously the review of the risk-benefit profile has led to the recommendation of use and dosage in special populations, eg for antiviral and anti-tubercular drugs (EMEA, 2009; EMA, 2012).

However, this recommendation does not translate into an automatic update of the Summary of Product Characteristics 

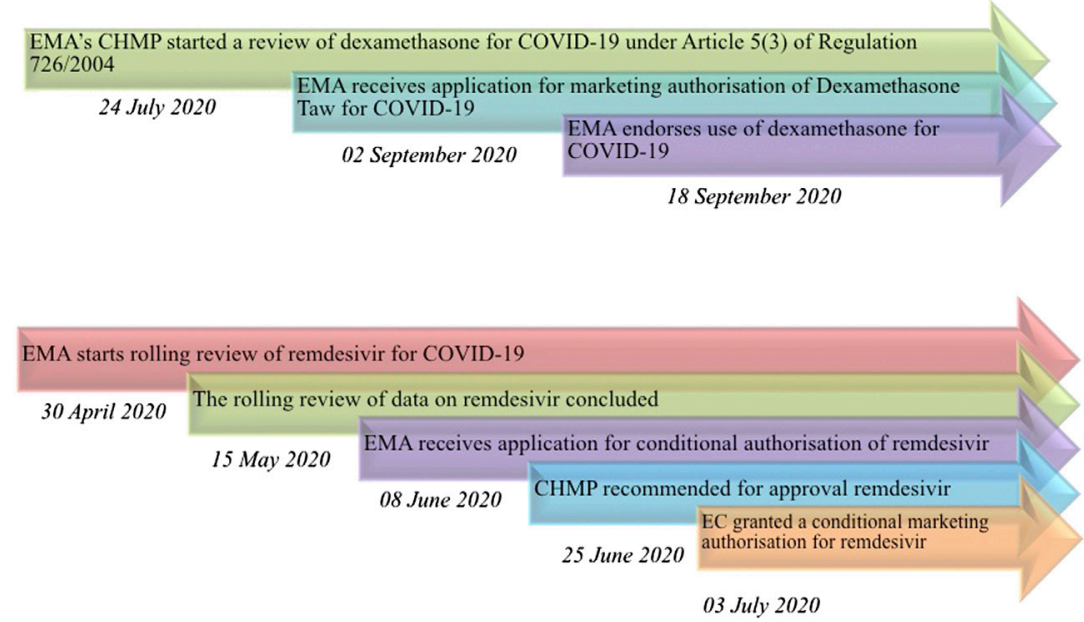

FIGURE 1 | Timeline of drugs' assessment performed by EMA for Covid-19. (A) desamethasone; (B) remdesivir. EMA: European Medicines Agency; CHMP: Committee for Medicinal Products for Human Use; EC: European Commission.

(SmPC), and the marketing authorization holders can request to add the new therapeutic use to their product's license by submitting an application to national regulatory authorities or EMA.

To date EMA received an application from Taw Pharma for the authorization of an injectable dexamethasone for treating hospitalized patients with Covid-19 (EMA, 2020d). The application will be evaluated by the CHMP according to an accelerated assessment. This will enable to issue an opinion within the shortest possible time.

The procedure allowed to deliver the opinion in less than two months (Figure 1A). On the other hand, the rapid assessment of the only drug approved for Covid-19, remdesivir, starting with the emergency procedure of the rolling review, has been completed in almost the same timeframe (Figure 1B). In this case, after the issue of conditional approval, EMA also implemented the Emergency Support Instrument (ESI) and subsequently a joint procurement contract in order to guarantee access to the drug throughout Europe (EC, 2020a; EC 2020b).

After CHMP opinion issued about dexamethasone on September 18th' 2020, the European national authorities have not implemented yet any procedure to guarantee access to the drug. In particular, waiting for the conclusive EMA approval following the companies' application for the final authorization of the new indication, some Member States have the possibility to recognize the nation-wide off-label use according to specific laws. For example, in Italy it is possible to include the off-label use in Covid-19 patients into the List of drugs reimbursed according to Law 648/96, whereas France may start a Temporary recommendation for use (RTU) program. Currently, no such action has been taken.

On October 6th the Italian Medicines Agency (AIFA) published a document with information useful to guide the prescription of corticosteroid in patients with Covid-19 (AIFA, 2020). However, the use has not been officially approved by the same Agency, so the treatment still falls within the scope of the off-label legislation, the so-called "Di Bella Law" (Gozzo et al., 2020; Di Bella, 2010), which allows the physicians to perform offlabel prescriptions in individual and exceptional cases, unless the local Health Director of the hospital formally authorize case by case the use. Anyway, the NHS does not cover the cost of the treatment. The only case in which an off-label use can be reimbursed in Italy is about drugs included in specific lists under the Law 648/1996 (Law 648, 1996). In this context, during the emergency AIFA provisionally endorsed the use and reimbursement of some drugs, such as hydroxychloroquine/cloroquine, lopinavir/ritonavir, and darunavir/cobicistat, despite the non-applicability of the Law $648 / 1996$, subsequently revoked due to the lack of data supporting a favorable risk-benefit profile (Gozzo et al. 2020).

Similarly, two decrees have been published by the French Ministry of Solidarity and Health, governing the prescription, dispensing and administration of hydroxychloroquine for patients with Covid-19:

The Decree n. 2020-314 of March 25, 2020 and n. 2020-337 of March 26, 2020 authorized the prescription, dispensation and administration of hydroxychloroquine and the combination of lopinavir/ritonavir "under the responsibility of a doctor to patients affected by Covid-19, in the health establishments which take charge of them", "in particular, for patients with oxygendemanding pneumonia or organ failure" (Ministère Des Solidarités Et De La Santé, 2020a; Ministère Des Solidarités Et De La Santé, 2020b).

In this case, these drugs were supplied and paid by health institutions.

Finally, even the French government revoked the decrees that allowed to prescribe hydroxychloroquine, due to the lack of proof of benefit and the health risks (Ministère Des Solidarités Et De La Santé, 2020c).

Given the positive and well-established findings that the drug is currently the only one preventing the mortality of patients, 
actions to ensure uniform and controlled access to corticosteroids for Covid-19 should be put in place as soon as possible.

The need to fill this regulatory gap is even stronger in light of the recently published interim results of the Solidarity Trial (Dyer, 2020; WHO, 2020; WHO Solidarity trial consortium, 2020).

The study supported by the World Health Organization is one of the largest international randomized trials for Covid-19 treatments, enrolling almost 12,000 patients in over 30 countries and evaluating the effect of drugs on important outcomes such as mortality, need for assisted ventilation and duration of hospitalization.

The preliminary results show little or no effect on these hard endpoints for the four treatments evaluated (remdesivir, hydroxychloroquine, lopinavir/ritonavir and interferon).

These findings confirm that till now only corticosteroids have proven effective in severe and critical Covid-19 patients. It is noteworthy to emphasize that these data come from welldesigned clinical trials that it was possible to rapidly start and efficiently conduct despite the emergency status, giving the first specific and evidence-based (although adjustable following future studies) guidance to clinicians on how to manage patients with Covid-19.

\section{CONCLUSION}

A lot of molecules have been tested in Covid-19 patients, but few positive results have been obtained.

\section{REFERENCES}

AIFA (2020). Corticosteroidi nella terapia dei pazienti adulti con COVID-19. Available at: https://www.aifa.gov.it/documents/20142/1123276/Corticosteroidi_ 06.10.2020.pdf/075c9302-895c-4d7e-11bc-0e2319082ffc (Accessed October 6, 2020).

Council Regulation (1993) Council Regulation (EEC) No. 2309/93 laying down community procedures for the authorization and supervision of medicinal products for human and veterinary use and establishing a European agency for the evaluation of medicinal products. Official Journal of the European Communities 214, 0001-0021.

Di Bella, G. (2010). The di Bella method (DBM). Neuro Endocrinol. Lett. 31 (Suppl. 1), 1-42.

Dyer, O. (2020) Covid-19: remdesivir has little or no impact on survival, WHO trial shows. BMJ 371, m4057. doi:10.1136/bmj.m4057. PMID: 33077424.

EC (2020b). Coronavirus: Commission signs a joint procurement contract with Gilead for the supply of Remdesivir. Available at: file://C:/Users/cometico/ Downloads/Coronavirus_Commission_signs_a_joint_procurement_contract_ with_Gilead_for_the_supply_of_Remdesivir_.pdf (Accessed October 8, 2020).

EC (2020a). European commission secures EU access to Remdesivir for treatment of covid-19. Available at: file:///C:/Users/cometico/Downloads/European Commission_secures_EU_access_to_Remdesivir_for_treatment_of_COVID-19. pdf (Accessed July 29, 2020).

EMA (2012) EMA/227191/2012. Assessment report review under article 5(3) of regulation (EC) No. 726/2004 anti-tuberculosis medicinal products containing isoniazid, rifampicin, pyrazinamide, ethambutol, rifabutin: posology in children procedure no: EMEA/H/A-5(3)/1310. Available at: https://www.ema.europa.eu/en/documents/ referral/assessment-report-article-53-procedure-anti-tuberculosis-medicinal-productscontaining-isoniazid_en.pdf (Accessed March 2, 2020).
Regulatory authorities react to the emergency adopting a number of measures in order to accelerate drug development and assessment process of available results.

The European procedure regulated by the Article five of the Regulation (EC) No 726/2004 allows to start independently from company interest the assessment of drugs potentially useful for unmet need, such as Covid-19.

However, currently this advantage in terms of time and resource seems to be lost due to the lack of an automatic transferability for prescription in clinical practice, in particular in this emergency situation.

It is dramatically important to rapidly overcome this regulatory gap to made widely available dexamethasone and corticosteroid in general, the only therapeutic option which demonstrated clinical relevant results in Covid-19 so far.

\section{AUTHOR CONTRIBUTIONS}

LG wrote the first draft of the manuscript. FD checked and revised the draft manuscript. All authors contributed read, revised, and approved the submitted version.

\section{SUPPLEMENTARY MATERIAL}

The Supplementary Material for this article can be found online at: https://www.frontiersin.org/articles/10.3389/fphar.2020.621934/ full\#supplementary-material

EMA (2020b). EMA endorses use of dexamethasone in covid-19 patients on oxygen or mechanical ventilation. Available at: https://www.ema.europa.eu/en/ news/ema-endorses-use-dexamethasone-covid-19-patients-oxygen-mechanicalventilation (Accessed September 18, 2020).

EMA (2020d). EMA receives application for marketing authorisation of Dexamethasone taw for covid-19. Available at: https://www.ema.europa.eu/en/news/ema-receivesapplication-marketing-authorisation-dexamethasone-taw-covid-19 (Accessed September 2, 2020).

EMA (2020a). EMA starts review of dexamethasone for treating adults with covid-19 requiring respiratory support. Available at: https://www.ema.europa.eu/en/news/ ema-starts-review-dexamethasone-treating-adults-covid-19-requiring-respiratorysupport (Accessed July 24, 2020).

EMA (2020c). Outcome of Art 5(3) procedure-product information (for dexamethasone only-containing oral or IV medicinal products). Available at: https://www.ema.europa.eu/en/documents/other/dexamethasone-covid19article-53-procedure-proposals-product-information_en.pdf (Accessed October 22, 2020)

EMEA (2009) EMEA/H/A-5.3/1172 Ref. EMEA/CHMP/278838/2009 opinion of the committee for medicinal products for human use pursuant to article 5(3) of regulation (EC) no 726/2004, on novel influenza (H1N1) outbreak Tamiflu (oseltamivir) Relenza (zanamivir). Available at: https://www.ema.europa.eu/en/ documents/other/opinion-chmp-pursuant-article-53-regulation-ec-no-726/2004-novelinfluenza-h1n1-outbreak-tamiflu-oseltamivir-relenza-zanamivir_en.pdf (Accessed May 7, 2007).

Gozzo, L., Longo, L., Vitale, D. C., and Drago, F. (2020). The regulatory challenges for drug repurposing during the covid-19 pandemic: the Italian experience. Front. Pharmacol. 11, 588132. doi:10.3389/fphar.2020.588132

Law 648 (1996). Conversione in legge del decreto-legge 21 ottobre 1996, n. 536, recante misure per il contenimento della spesa farmaceutica e la rideterminazione del tetto di spesa per l'anno. Available at: https://www.gazzettaufficiale.it/atto/serie_generale/ 
caricaDettaglioAtto/originario?atto.dataPubblicazioneGazzetta=1996-12-23\&atto. codiceRedazionale=096G0680\&elenco30giorni=false (Accessed October 21, 1996).

Ledford, H. (2020). Coronavirus breakthrough: dexamethasone is first drug shown to save lives. Nature 582 (7813), 469. doi:10.1038/d41586-020-01824-5.

Ministère Des Solidarités Et De La Santé (2020c). Avis du Haut Conseil à la Santé Publique relatif à l'utilisation de l'hydroxycholoroquine dans le covid-19: le Gouvernement prend un décret modifiant le cadre de prescription. Available at: https://solidarites-sante.gouv.fr/IMG/pdf/200527-_cp_hydroxychloroquine.pdf (Accessed October 2020).

Ministère Des Solidarités Et De La Santé (2020a). Décret n 2020-314 du 25 mars 2020 complétant le décret n ${ }^{\circ} 2020-293$ du 23 mars 2020 prescrivant les mesures générales nécessaires pour faire face à l'épidémie de covid-19 dans le cadre de l'état d'urgence sanitaire NOR: SSAZ2008362D. Available at: https://www. legifrance.gouv.fr/eli/decret/2020/3/25/SSAZ2008362D/jo/texte (Accessed March 26, 2020).

Ministère Des Solidarités Et De La Santé (2020b). Décret no 2020-314 du 25 mars 2020 complétant le décret no 2020-293 du 23 mars 2020 Prescrivant les mesures générales nécessaires pour faire face à l'épidémie de covid-19 dans le cadre de l'état d'urgence sanitaire. Available at: https://www.legifrance.gouv.fr/ download/pdf?id=_bhGSZpQEI4f_HjbyCJsdOJEkRkiRL9VjTUPGPz6rP8= (Accessed March 26, 2020).

RECOVERY (2020a). Randomised evaluation of covid-19 therapy. Available at: https://www.recoverytrial.net/files/protocol-archive/recovery-protocolv2-0-2020-03-23.pdf (Accessed March 23, 2020).

RECOVERY (2020b). Randomised evaluation of covid-19 therapy. Available at: https://www.recoverytrial.net/files/protocol-archive/recovery-protocolv3-0-final-2020-04-07.pdf (Accessed April 7, 2020).

RECOVERY (2020c). Randomised evaluation of covid-19 therapy. Available at: https://www.recoverytrial.net/files/protocol-archive/recovery-protocolv4-0-2020-04-14.pdf (Accessed April 14, 2020).

RECOVERY (2020d). https://scholar.google.com/scholar?hl=en\&as_sdt $=0 \%$ 2C5\&q=Randomised+evaluation+of+covid-19+therap\&btnG=y. Available at: https://www.recoverytrial.net/files/protocol-archive/recovery-protocolv6-0-2020-05-14.pdf (Accessed May 14, 2020).

RECOVERY (2020e). Randomised evaluation of covid-19 therapy. Available at: https://www.recoverytrial.net/files/recovery-protocol-v7-0-2020-06-18. pdf (Accessed June 18, 2020).

RECOVERY Collaborative Group (2020a). Lopinavir-ritonavir in patients admitted to hospital with covid-19 (recovery): a randomised, controlled, open-label, platform trial. Lancet 396 (10259), 1345-1352. [Epub ahead of print]. doi:10.1016/S0140-6736(20)32013-4

RECOVERY Collaborative Group, Horby, P., Lim, W. S., Emberson, J. R., Mafham, M., Bell, J. L., Linsell, L., et al. (2020b). Dexamethasone in hospitalized patients with covid-19-preliminary report. N. Engl. J. Med. [Epub ahead of print].

Regulation EC (2004) Regulation (EC) No 726/2004 of the European Parliament and of the council laying down community procedures for the authorisation and supervision of medicinal products for human and veterinary use and establishing a european medicines agency. Official Journal L 136, 0001-0033.

University of Oxford (2020). Recovery. randomised evaluation of covid-19 therapy. Available at: https://www.recoverytrial.net/ (Accessed November 4, 2020).

WHO Rapid Evidence Appraisal for COVID-19 Therapies (REACT) Working Group, (2020). Sterne, J. A. C., Murthy, S., Diaz, J. V., Slutsky, A. S., Villar, J., Angus, D. C., et al. Association between administration of systemic corticosteroids and mortality among critically ill patients with covid-19: a meta-analysis. J. Am. Med. Assoc. 324 (13), 1-13. [Epub ahead of print]. doi:10. 1001/jama.2020.17023

WHO Solidarity trial consortium. (2020). Repurposed antiviral drugs for covid19-interim who solidarity trial results. MedRxiv [Preprint]. Available at: https://doi.org/10.1101/2020.10.15.20209817 (Accessed November 15, 2020).

WHO (2020). "Solidarity" clinical trial for covid-19 treatments. Available at: https://www.who.int/emergencies/diseases/novel-coronavirus-2019/globalresearch-on-novel-coronavirus-2019-ncov/solidarity-clinical-trial-for-covid-19treatments (Accessed October 15, 2020).

Conflict of Interest: The authors declare that the research was conducted in the absence of any commercial or financial relationships that could be construed as a potential conflict of interest.

Copyright (c) 2020 Gozzo, Longo, Vitale and Drago. This is an open-access article distributed under the terms of the Creative Commons Attribution License (CC BY). The use, distribution or reproduction in other forums is permitted, provided the original author(s) and the copyright owner(s) are credited and that the original publication in this journal is cited, in accordance with accepted academic practice. No use, distribution or reproduction is permitted which does not comply with these terms. 